\title{
Streik („,Grève“)
}

Das Recht auf Streik ist ein fundamentales Recht, das von der Verfassung, vom Arbeitsgesetzbuch und von verschiedenen internationalen, von Frankreich ratifizierten, Bestimmungen anerkannt und geschützt wird. Es kann nicht durch Tarifvertrag begrenzt oder reglementiert werden.

Der Begriff des Streiks wird nicht durch das Gesetz definiert. Aber nach der Rechtsprechung, die die Kriterien vorgegeben hat, handelt es sich dabei um eine kollektive und abgestimmte Aussetzung der Arbeit durch das Personal eines oder mehrerer Unternehmen, die darauf abzielt, berufliche Ansprüche durchzusetzen. Der Streik muss demnach gemeinsam durchgeführt werden. Er kann nicht durch eine einzige Person durchgeführt werden. Die Arbeitnehmer müssen ihre Arbeit im Einvernehmen beenden und die gemeinsame Absicht verfolgen, berufliche Forderungen durchsetzen zu wollen. Die letztgenannten Forderungen müssen einen beruflichen Hintergrund haben und sich auf Rechte erstrecken, die die Streikenden direkt betreffen.

Der Arbeitgeber ist davon befreit, dem streikenden Arbeitnehmer das Gehalt auszuzahlen, genauso wie seine Lohnzuschüsse und Lohnnebenleistungen. Im Gegensatz dazu können die während des internen Streiks verlorenen Stunden nicht zurückverlangt werden. Eine Vereinbarung, die die Streiks beendet, kann jedoch die Zurückgewinnung von verlorenen Stunden vorsehen, die dann mit einem Überstundensatz ausbezahlt werden.

Der streikende Arbeitnehmer kann nicht entlassen werden, außer im Falle einer groben Verschuldung (,Faute lourde“), die ihm zugerechnet wird. 